\title{
Spinal Schwannoma Kistik Intradura
}

\author{
Ira Safitri ${ }^{1}$, Rully Hanafi ${ }^{2}$, Farhan Anwary ${ }^{3}$
}

\begin{abstract}
ABSTRAK
Spinal schwannoma kistik intradura merupakan jenis tumor yang jarang ditemukan. Schwannoma merupakan tumor jinak yang berkembang dari sel Schwann yang terdapat pada lapisan pembungkus saraf dan merupakan tumor spinal intradura yang paling sering ditemukan. Umumnya tumor schwannoma spinal merupakan massa solid atau solid heterogen dan jarang ditemukan dalam bentuk kistik.

Suatu kasus, seorang laki-laki umur 43 tahun datang dengan keluhan utama lemah kedua tungkai. Sejak 2,5 bulan sebelumnya pasien merasakan nyeri tulang ekor menjalar ke tungkai kanan dan bertahap diikuti keluhan lemah tungkai kanan. Selanjutnya diikuti dengan nyeri dan kesemutan kaki kiri dan kemudian dirasakan kelemahan kaki kiri dan sulit defekasi dan miksi sejak 1 bulan sebelum masuk rumah sakit. Pemeriksaan Magnetic Resonance Imaging (MRI) lumbosacral dengan kontras menunjukkan gambaran lesi kistik, sebagian bersepta-septa, intradura, mengobliterasi canalis spinalis setinggi corpus vertebra torakal 12 sampai sacral 2 yang memberikan enhancement terhadap kontras pada septa dan tepinya. Pasien menjalani operasi laminektomi dan didapatkan massa tumor intradura, berbatas tegas dengan cord dan radix berbentuk tubular sepanjang $20 \mathrm{~cm}$, dengan bagian yang kistik berisi cairan kental kekuningan dan bagian yang solid berwarna merah kebiruan mudah berdarah, tidak berkapsul, berbatas tegas, spinal cord terdorong ke anterosuperior, cauda equina terdorong ke lateral kanan dan kiri, tumor terangkat $100 \%$. Secara makroskopis saat operasi, massa tumor di duga sebagai myxopapillary ependymoma.Pemeriksaan patologi anatomi kemudian memastikan bahwa tumor tersebut adalah schwannoma. Setelah operasi keadaan pasien membaik dengan perbaikan motorik pada kedua tungkainya.
\end{abstract}

Kata kunci: Schwannoma, kistik, bersepta, intradura, spinal.

\section{PENDAHULUAN}

Spinal schwannoma intradura adalah tumor jinak yang merupakan $30 \%$ dari tumor primer spinal.Umumnya schwannoma merupakan tumor solid ataupun solid heterogen dan jarang sekali berbentuk kistik, hanya ada sekitar 10 kasus yang telah dilaporkan dalam literatur. ${ }^{1,2}$

Daerah lumbal merupakan tempat tersering terjadinya schwannoma spinal, menurut Conti dkk., yang meneliti distribusi dari spinal schwannoma sekitar $48 \%$ spinal schwannoma terdapat di daerah lumbal. Prevalensi schwannoma di lumbal tidaklah jarang akan tetapi predominan kistik schwannoma

\footnotetext{
Fakultas Kedokteran Univ.Riau, Departemen Radiologi RSHS/FK Unpad

Departemen Bedah Saraf RSHS/FK Unpad

Departemen Radiologi RSHS/FK Unpad
}

ukuran besar di daerah lumbal sangat jarang terjadi meskipun telah diketahui bahwa schwannoma jinak dapat mengalami degenerasi membentuk formasi kistik, kalsifikasi, perdarahan dan hyalinisasi. ${ }^{3,4}$

Menarik diketahui schwannoma di daerah lumbal dapat terjadi tanpa disadari dalam waktu lama karena pertumbuhan tumor yang lambat sehingga timbulnya gejala klinis biasanya jika ukuran tumor sudah besar dan menyebabkan penekanan pada saraf.Gambaran struktur kistik schwannoma yang jarang ditemukan menjadi tantangan dalam penegakkan diagnosis

\section{LAPORAN KASUS}

Seorang laki-laki umur 43 tahun datang dengan keluhan utama lemah kedua tungkai. Sejak 2,5 bulan sebelumnya pasien merasakan nyeri tulang ekor 
menjalar ke tungkai kanan dan bertahap diikuti keluhan lemah tungkai kanan. Selanjutnya diikuti dengan nyeri dan kesemutankaki kiri dan kemudian dirasakan kelemahan kaki kiri dan sulit defekasi dan miksisejak 1 bulan sebelum masuk rumah sakit.Pasien dirawat 5 hari di RS Mitra Kasih Cimahi, dilakukan pemeriksaan x-ray lumbosacral dengan kesimpulan spondilolistesis L5-S1 dan dirujuk ke Rumah Sakit Hasan Sadikin.

Pemeriksaan fisik pasien didapatkan kesadaran komposmentis, tanda vital normal, pasien tidak ada riwayat trauma tulang, penurunan berat badan ataupun stroke. Pemeriksaan neurologis menunjukkan adanya penurunan kekuatan motorik ekstremitas inferior bilateral menjadi $3 / 3$, gangguan sensorik berupa hipestesi setinggi radiks spinalis lumbal 3-4 dan gangguan proprioseptif setinggi lumbal 4-5 dan lumbal 5-sacral 1.

Diagnosis sementara dari hasil pemeriksaan fisik dan neurologis disimpulkan sebagai cauda equina syndrome dengan etiologi diduga akibat penekanan oleh tumor di diagnosis banding dengan infeksi.

Pemeriksaan laboraturium hematologi dan kimia klinik menunjukkan masih dalam batas normal, tidak terdapat tanda-tanda adanya infeksi.

Pemeriksaan x-rays torak dan torakolumbal masih dalam batas normal Pemeriksaan lanjutan dilakukan Magnetic Resonance Imaging (MRI) lumbosacral dengan kontras.

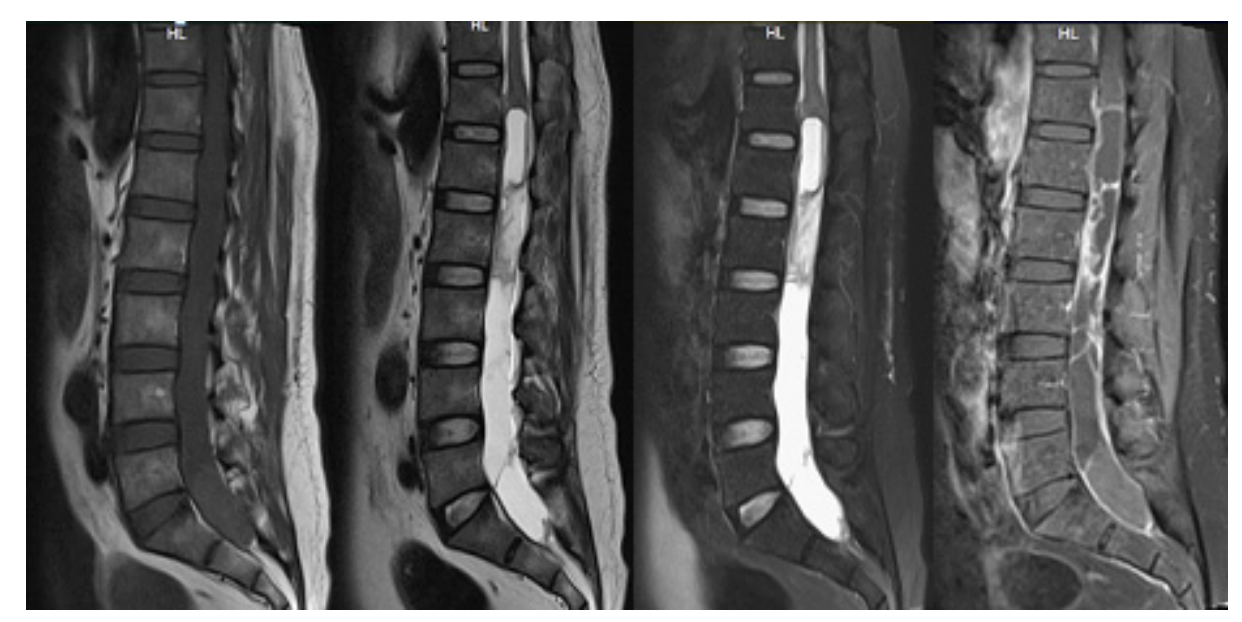

Gambar 1. MRI potongan sagittal T1-weighted dan T2-Weighted, STIR dan T1-FS dengan kontras memperlihatkan lesi kistik, sebagian bersepta-septa yang mengobliterasi canalis spinalis setinggi vertebra torakal 12 sacral 2

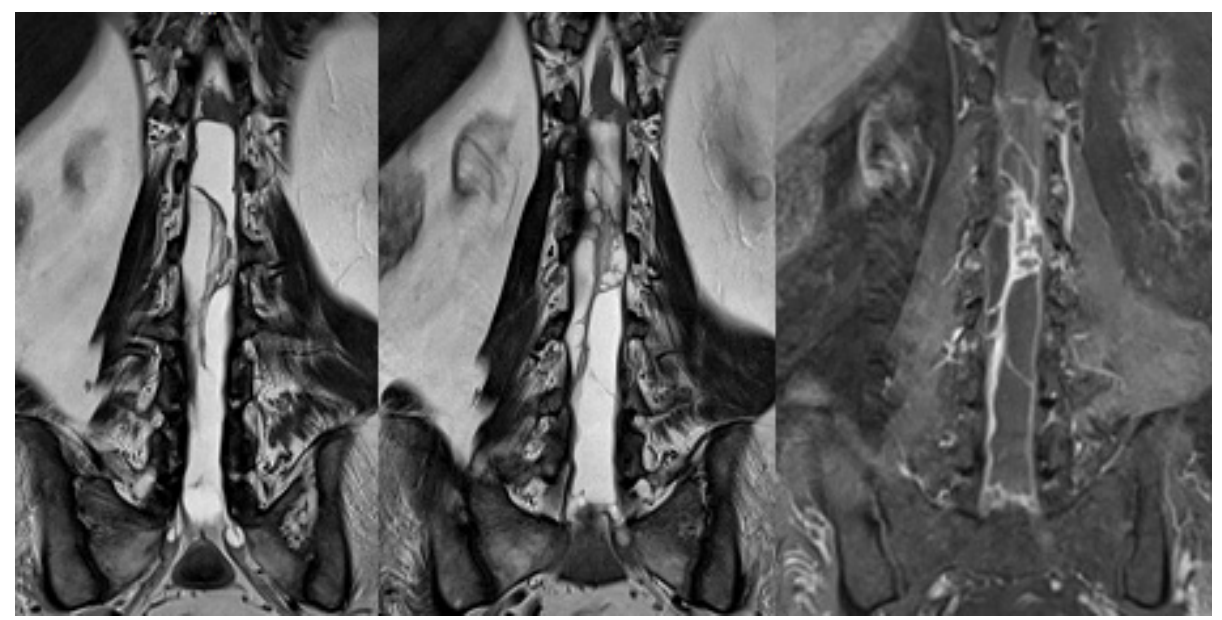

Gambar 2. MRI potongan coronal T2-weighted, memperlihatkan lesi kistik hiperintens, bersepta yang mendesak spinal cord ke superior. Pada pemeriksaan T1-FS dengan kontras septa tampak memberikan enhancement 


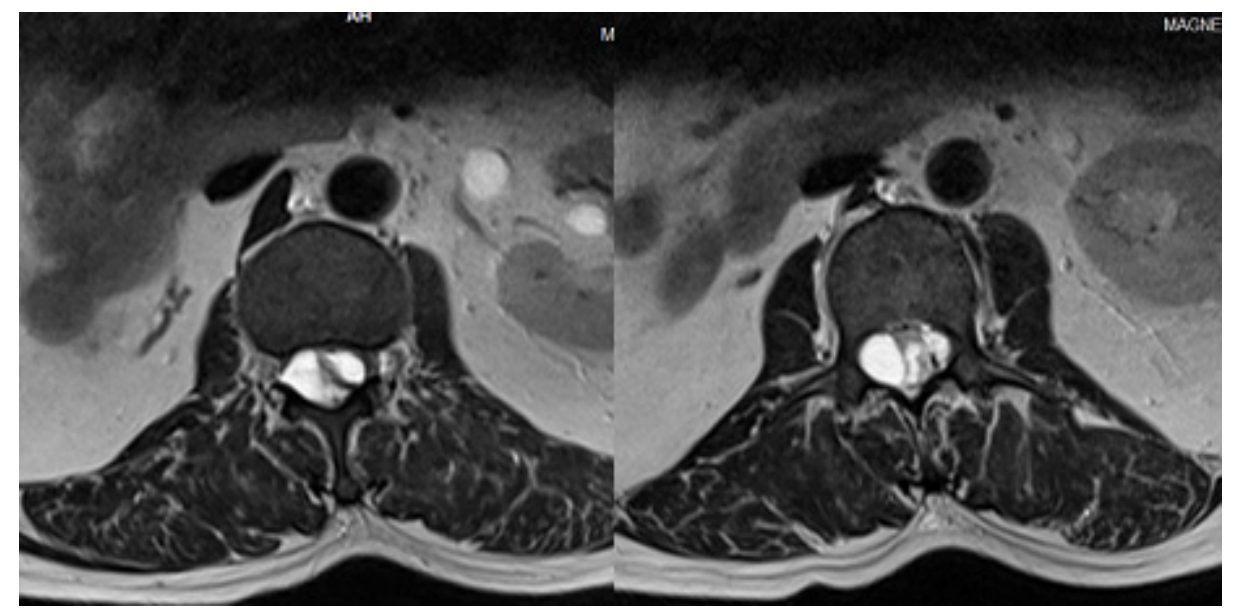

Gambar 3. MRI potongan aksial T2-weighted, setinggi lumbal 1-2 memperlihatkan lesi kistik dengan signal hiperintens yag menekan ke daerah radiks spinalis bilateral terutama kanan.

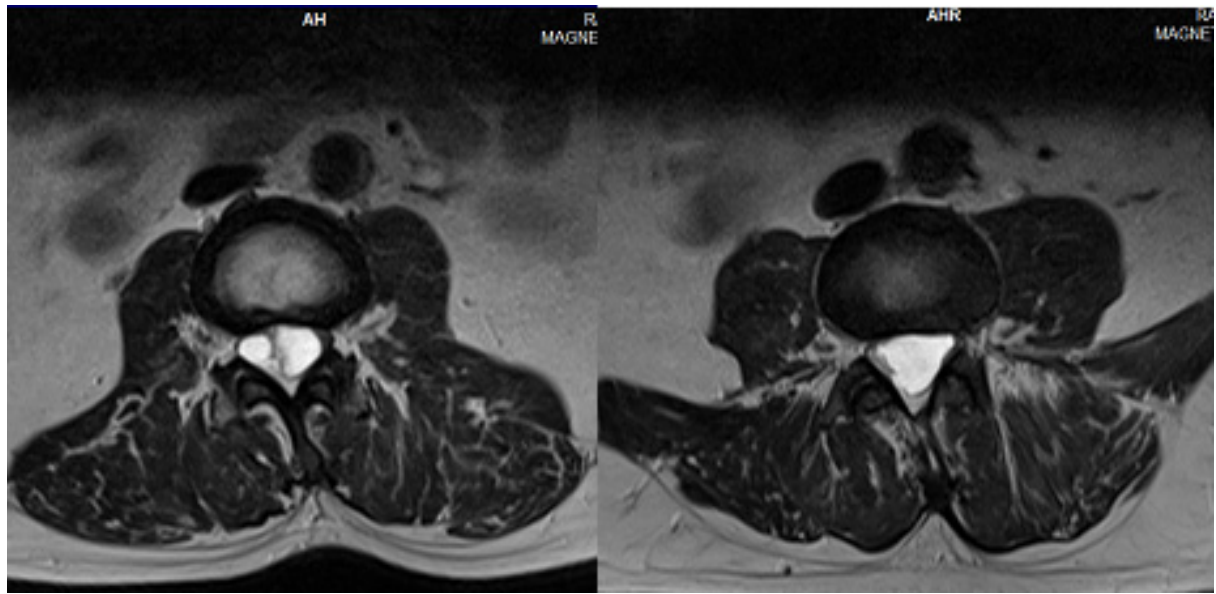

Gambar 4. MRI potongan aksial setinggi lumbal 2-3 sampai sacral 2 memperlihatkan lesi kistik di dalam canalis spinalis yang menekan radiks spinalis bilateral terutama kiri.

Pada potongan sagital MRI T1-weighted tampak curve lurus dengan alignment vertebra lumbosacral masih baik, tampak lesi kistik hipointens, batas tegas yang mengobliterasi canalis spinalis mulai setinggi torakal 12 sampai sacral 2 dengan pelebaran dari canalis spinalis di daerah tersebut. T1-weighted imaging memperlihatkan intesitas signal lesi yang lebih rendah dibandingkan dengan medulla spinalis. Potongan sagital MRI T2weighted memperlihatkan perubahan intensitas signal lesi menjadi hiperintens dengan sebagian tampak bersepta-septa dan pada pemberian kontras memberikan enhancement pada septa dan tepinya. Neuro foramina intervertebralis lumbosacral kiri dan kanan masih tampak normal.

MRI potongan aksial menunjukkan lesi kistik hipointens pada T1-weighted dan hiperintens pada
T2-weighted yang mengisi canalis spinalis, intradural dan tampak menekan radix spinalis kiri dan kanan. Pada potongan aksial ini sulit untuk menentukan apakah lesi tersebut berada intramedulla atau ekstramedulla karena potongan aksial dilakukan mulai setinggi corpus vertebra lumbal 2 dimana umumnya terdapat hanya cauda equina, fillum terminale dan radix spinalis.

MRI potongan coronal T1-weighted dengan kontras menunjukkan lebih jelas lesi kistik hipointens dengan septa-septa yang memberikan enhancement dan mengobliterasi canalis spinalis mulai setinggi corpus vertebra torakal 12 sampai sacral 2 dan tampak mendesak spinal cord ke superior. 
Kesimpulan MRI didiagnosa sebagai lesi kistik, sebagian bersepta-septa, intradura, yang mengobliterasi canalis spinalis setinggi corpus vertebra torakal 12 sampai sacral 2.

Kasus ini kemudian dilakukan join conference antara bagian neurologi, neurosurgery dan radiologi. Hasilnya disimpulkan etiologi sementara berupa diagnosis banding antara ependymoma dan kistik schwannoma. Kemudian pasien alih rawat dengan direncanakan operasi laminectomy segera karena kekuatan motorik inferior bilateral semakin menurun, tindakan operasi diharapkan akan memperbaiki keadaan pasien.

Pasien kemudian dilakukan operasi laminectomy tumor removal, hasil operasi di dapatkan massa tumor intradura, berbatas tegas dengan cord dan radiks berbentuk tubular sepanjang sekitar $20 \mathrm{~cm}$, dengan bagian yang kistik berisi cairan kental kekuningan dan bagian yang solid berwarna merah kebiruan mudah berdarah, tidak berkapsul, berbatas tegas, spinal cord terdorong ke anterosuperior, cauda equina terdorong ke lateral kanan dan kiri, tumor terangangkat $100 \%$.Hasil operasi massa tumor di duga sebagai myxopapillary ependymoma.

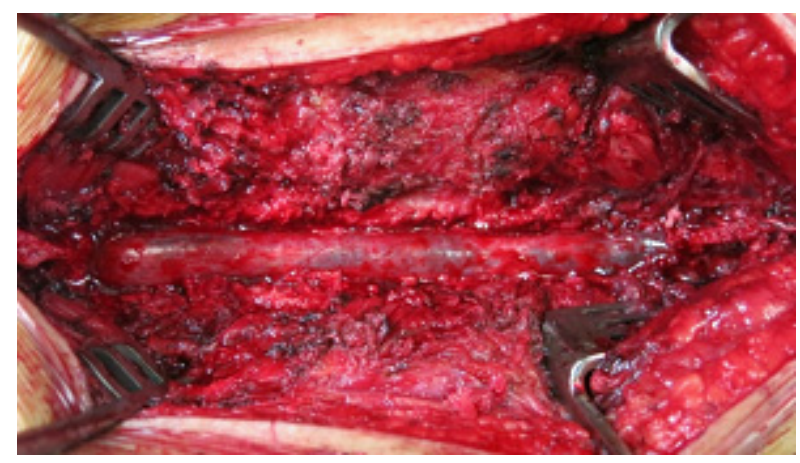

Gambar 5. Massa tumor berbentuk tubular di dalam canalis spinalis

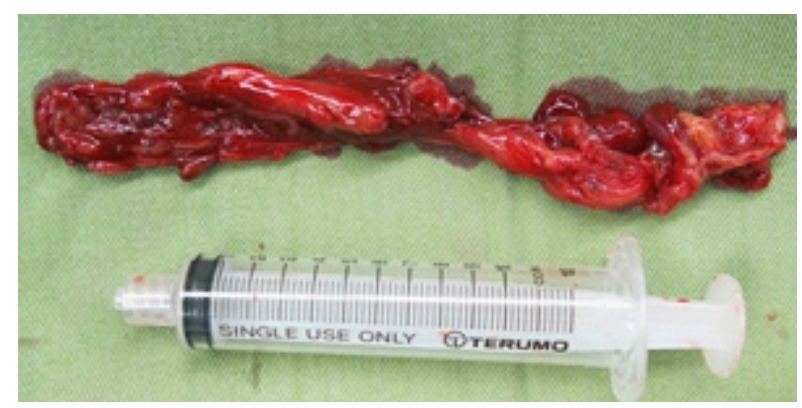

Gambar 6. Massa tumor terangkat seluruhnya.
Massa tumor kemudian dilakukan pemeriksaan patologi anatomi dengan pewarnaan hematoxillin eocyn dan pada pemeriksaan mikroskopis didapatkan massa tumor terdiri dari sel-sel berbentuk bulat, oval, sebagian spindle yang tumbuh hiperplastis, tersusun parallel sebagai storiform, inti sel bulat, oval, uniform, kromatin halus, mitosis sulit ditemukan. Pada stroma jaringan ikat diantaranya tampak dilatasi pembuluh darah dan daerah perdarahan.Tidak tampak sel ganas. Hasil pemeriksaan patologi anatomi disimpulkan sebagai Fibrous meningioma (WHO grade I) di diagnosis banding dengan fibroma dan schwannoma. Bagian patologi anatomi kemudian menyarankan pemeriksaan imunohistokimia untuk menegakkan diagnosis pasti dari jenis sel tumor tersebut.Selanjutnya dilakukan pemeriksaan imunohistokimia berupa pemeriksaan Vimentin yang menunjukkan hasil positif, artinya sel berasal dari jaringan mesenchym dan pemeriksaan S100 juga menunjukkan hasil positif sebagai schwannoma.

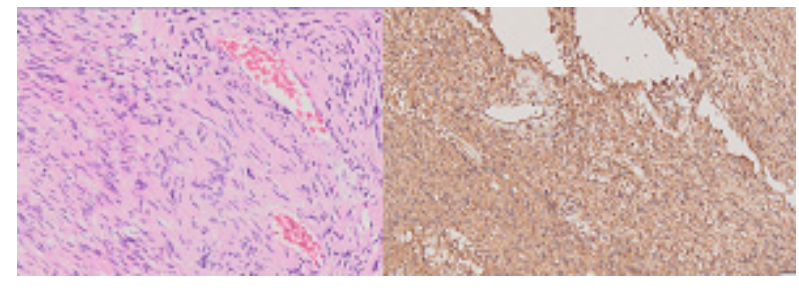

Gambar 7. Gambaran mikroskopis dengan pewarnaan HE dan S 100

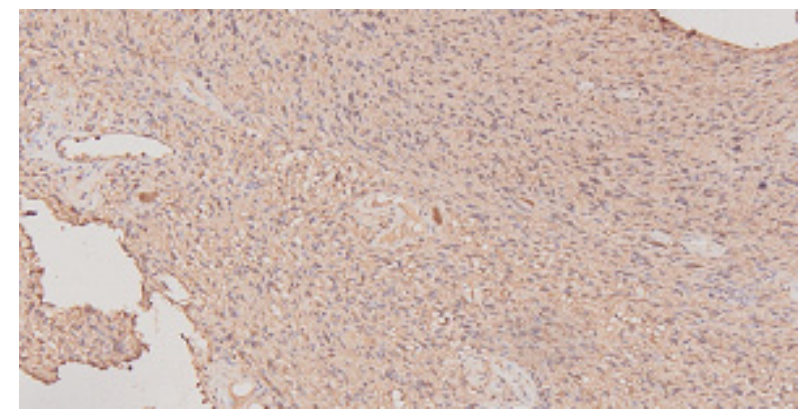

Gambar 8. Pemeriksaan imunohistokimia vimentin

\section{DISKUSI}

Spinal schwannoma intradural merupakan tumor jinak yang tumbuh lambat dan berasal dari sel-sel pembungkus saraf spinal spinal yaitu sel Schwann.Scwannnoma merupakan tumor intradural 
ekstramedulla yang paling sering dan umumnya solid atau heterogen solid, total kistik schwannoma sangat jarang ditemukan. ${ }^{4,5}$

Lokasi tersering dari spinal schwannoma adalah di daerah lumbar (48\%).Schwannoma dapat mengalami perubahan degenerative seperti fibrosis, kalsifikasi, hemoragik, ataupun kistik.Perubahan kistik pada schwannoma sangat jarang ditemukan di daerah vertebra lumbar dan baru 10 kasus yang pernah dilaporkan di literatur. ${ }^{1,6,7}$

Berbagai hipotesis teori diajukan untuk menjelaskan perubahan kistik pada Schwannoma, diantaranya nekrosis iskemik sentral, thrombosis pembuluh darah yang mengakibatkan nekrosis dan perdarahan atau neovaskularisasi tumor dapat mengakibatkan pertumbuhan tumor dengan bagian kistik di dalamnya.MRI diaggap sebagai modalitas terbaik untuk menggambarkan tumor spinal kistik. Umumnya schwannoma tampak memberikan signal hipointens pada T1-weighted dan intensits heterogen pada T2-weighted tergantung dari komponen di dalam schwannoma tersebut. Gambaran hipointens pada T2-weighted di MRI sering berhubungan dengan perdarahan, densitas seluler atau deposit kolagen, sedangkan hiperintensitas menunjukkan adaya perubahan kistik.Diagnosis banding secara radiologis dapat berupa neurinoma kistik, ependimoma, kista neurenterik, kista tarlov dan kista arachnoid. Penggunaan kontras dipilih untuk membedakan schwannoma dengan neoplasma lainnya. Rim enhancement dari intradural ekstramedullar tumor pada MRI harus dipertimbangkan sebagai schwannoma, meskipun diagnosis pasti ditegakkan dengan pemeriksaan histopatologis. Gejala klinis umumnya terjadi akibat penekanan saraf radiks spinalis daerah lumbal dan karean pertumbuhannya yang lambat gejala klinis berat biasanya terjadi setelah ukuran massa membesar dan menekan radik spinalis. Intervensi bedah disarankan jika terjadi deficit neurologis yang progresif. Eksisi total merupakan pilihan terbaik untuk meminimalisir kekambuhan dan meningkatkan peluang kesembuhan. ${ }^{1}$

\section{DAFTAR PUSTAKA}

1. Santhosh K, Kesavadas C, Thomas B, Gupta AK, KapilamoorthyTR, Radhakrishnan VV. Fluidfluid levels in cystic lumbosacral schwannomas: a report of three cases. Singapore Med J. 2009;50: e16-e21.

2. Cheng-Ta Hsieh, MD, Wen-Chiuan Tsai, MD, Ming-Ying Liu, MD. Intradural lumbar cystic schwannoma A case report.Neurosciences Journal 2011; Vol. 16 (4): 366-368

3. Conti P, Pansini G, Mouchaty H, Capuano C, Conti R. Spinal neurinomas:re t rospective analysis and long-term outcome of 179 consecutivelyoperated cases and review of the literature. Surg Neurol 2004;61:34-43

4. Guilherme Borges, Leonardo Bonilha, Marcílio Proa Jr., Yvens Barbosa Fernandes, Ricardo Ramina, Veronica Zanardi, Jose Ribeiro Menezes. Imaging features and treatment of an intradural lumbar cystic schwannoma. A case report. Arq Neuropsiquiatr journal 2005;63(3A):681-684

5. Liu WC, Choi G, Lee SH, Han H, Lee JY, Jeon $\mathrm{YH}$, et al.Radiological findings of spinal schwannomas andmeningiomas: focus on discrimination of two disease entities.Eur Radiol 2009; 19:2707-15.

6. Rana Netra, Ma Shao Hui, Min Zhi Gang and Zhang Ming. Spinal Cystic Schwannoma: An MRI Evaluation.Journal of the College of Physicians and Surgeons Pakistan 2014, Vol. 24 (2): 145-147.

7. Marc D. Haber, MD, Dustin D. Nguyen, DOShan Li, MD, MS. Differentiation of Idiopathic Spinal Cord Herniation from CSF-isointense Intraspinal Extra-medullary Lesions Displacing the Cord. RadioGraphics Journal 2014; 34:313-329

8. Desheng $\mathrm{Wu}, \mathrm{MD}$; Zhaoyu Ba, MD; Yufeng Huang, MD; Weidong Zhao, MD; Bin Shen, MD; Heng Kan, MD. Totally Cystic Schwannoma of the Lumbar Spine. A case report. Healio orthopedics journal 2013: vol.35:5

9. Manish Kumar K, Shashank S. K., Bhawani Shanker S., Vaishali S., Totally Cystic Intradural Extramedullary Schwannoma. A case report. Turkish Neurosurgery 2008, Vol: 18, No: 4, 404406 